\title{
Atributos Gráficos da Heráldica em Marcas Comerciais
}

\author{
Graphic attributes of heraldic brands
}

\author{
por André Ricardo Paim de Campos, \\ Eduardo Napoleão e Richard Perassi Luiz de Sousa
}

\section{RESUMO}

Este trabalho apresenta resultados de estudos teóricos e documentais, descrevendo a aplicação interpretativa dos conhecimentos obtidos sobre Heráldica Medieval, como a arte de conceber brasões, no estudo das marcas institucionais e comerciais contemporâneas. 0 contexto é composto pelas áreas de Cestão de Design e Cestão da Marca ou Branding. Tradicionalmente, os brasões foram usados para identificação de alguém ou de algum lugar, sendo que a vasta simbologia empregada ainda é pouco conhecida. Os resquícios das regras, das formas, dos tratamentos e das cores usadas na composição heráldica ainda subsistem e influenciam as marcas gráficas, nas suas formas de representação de organizações, produtos ou serviços. Além da casualidade, indica-se que a motivação para o uso dos atributos pode ser estabelecida de acordo com referências diretas ou indiretas, sendo relacionadas ou não aos antigos símbolos de família ou território.

Palavras-chave heráldica; marca gráfica; gestão de design; branding; brasões

\section{ABSTRACT}

In the analysis of the ways citizens interact with the contemporary metropolis, This work shows theoric and documental studies about Medieval Heraldic and its interpretative applications, like blazon concepts, in the institutional and commercial contemporary brand studies. This study is located between Design Management and Branding studies. The blazons used to identify people and places, but now its symbolism is used to logo and branding design. The blazons symbols, shapes and colors are designed to work with logotypes on the organizations, products and services. The motivation to use the heraldic concepts is based in direct and indirect references, related or not to the old families and territorial symbols.

Keywords heraldic; logotypes; design management; branding; blazons 


\section{Introdução}

Este texto aplica conhecimentos do campo do design gráfico, gestão do design, branding e estudo de marcas gráficas institucionais e comerciais que, de maneira ampla, caracterizam um sistema cultural particular, que pode ser didaticamente percebido em duas partes. A primeira é a parte tangível e expressiva, ou seja, tudo que é percebido pelo público e associado à marca, como elemento de sua representação. As instalações, os automóveis, a folhetaria timbrada, os uniformes dos colaboradores e, também, suas atitudes, entre outros elementos são componentes da primeira parte. A segunda é a parte intangível ou mental, compondo a imagem da marca que ocupa as mentes do público (PERASSI, 2001 e COSTA, 2008).

A marca se estabelece, portanto, como produto resultante dos processos de comunicação, intencionais ou casuais, entre os elementos tangíveis de expressão e representação da marca e o público receptor nessa comunicação. Sendo assim, a área de Gestão da Marca ou Branding deve ocupar-se, de maneira prioritária, com a gestão da informação e, nesse contexto, com a gestão do design de informação, ainda, gerenciando o processo de comunicação organizacional como um todo. Para tanto, deve planejar estrategicamente as múltiplas ações de controle das aparições ou publicações de quaisquer elementos associados à imagem da marca, considerando-as como partes do processo de comunicação da marca (PERASSI, 2001 e 2010).

A síntese simbólica de todo o processo de comunicação da marca é sua "assinatura visual" ou "marca gráfica" (trademark) que, geralmente, é composta conjuntamente por um logotipo, como o nome da marca escrito de maneira particularizada, e por outro símbolo gráfico-visual, como uma imagem ou pictograma, que também representa a marca.

Os estudos desenvolvidos no presente artigo identificam e descrevem os elementos tradicionais de heráldica medieval em logotipos ou símbolos das marcas gráficas institucionais e comercias da atualidade.

Historicamente, o uso de brasões e elementos heráldicos configura uma forma de comunicação bastante peculiar. Atualmente, a influência da linguagem heráldica ainda permanece presente na origem e na visualidade de diversos símbolos no contexto contemporâneo.

Muito antes de serem usados por nobres e cavaleiros europeus, no ápice da Idade Média, os brasões, bandeiras e insígnias já figuravam entre os primeiros clãs humanos. Mas, percebe-se, também, que os escudos e brasões de armas de séculos passados deram origem aos artefatos simbólicos contemporâneos conhecidos como símbolos, logotipos ou marcas gráficas institucionais ou comerciais. É comum identificar nos símbolos atuais construções formais muito próximas aos preceitos originais da heráldica. Também é recorrente identificar estes mesmos elementos, quando aplicados em projetos gráficos para produtos de naturezas diversas, sejam 
garrafas de vinho ou embalagens de chocolate. Contudo, o desconhecimento da linguagem heráldica provoca o uso de seus elementos característicos como recursos decorativos, sem a prévia percepção de seu valor histórico-simbólico. Isso caracteriza o processo de "heraldização" descontextualizada, como recurso superficial para conferir aos produtos apelos de sofisticação, nobreza ou tradição. Com base nas relações histórico-regionais, entre outras, o gerenciamento sistêmico do processo simbólico possibilita a construção e o desenvolvimento de marcas que se beneficiem simbolicamente dos elementos heráldicos.

0 objetivo deste texto é promover conhecimento sobre aspectos contextuais e históricos dos elementos da arte heráldica, considerando sua aplicação gráfica na construção e desenvolvimento de marcas institucionais e comerciais. Para tanto, considera-se pontos de intersecção entre Heráldica e Design Gráfico, no contexto da identidade visual da marca nos processos de gestão da marca ou branding.

A pesquisa realizada é "Descritiva", prevendo a descrição e a interpretação dos dados. Assim, "observa, registra, correlaciona e descreve fatos ou fenômenos de uma determinada realidade sem manipulá-los" (VALETIM, 2005). Foram desenvolvidos estudos exploratórios, estudos teóricos, estudos históricos e, também, iconográficos.

\section{Aspectos histórico-contextuais}

A heráldica vai além da ciência, porque é ao mesmo tempo arte, consistindo no estudo e na interpretação de algumas regras, significados, origem e evolução dos símbolos e cores, ordenados segundo leis, e usados para identificar locais, pessoas e famílias. Como mencionam Matos e Bandeira (1969: 15), o objeto de estudo, portanto, são os brasões, escudos ou armas, representando ícones dos valores, origem e historia dos seus possuidores. E devido a esses acontecimentos, a heráldica apresenta tantas subdivisões quantas às espécies de pessoas que se queiram distinguir.

As principais leis da heráldica foram estabelecidas há cerca de mil anos, nas épocas de batalhas, quando os cavaleiros cobriam seus corpos com armaduras, elmos, luvas de forma tal que era praticamente impossível diferenciar um amigo de um inimigo. Na Idade Antiga era comum que certos tipos de insígnias fossem utilizados para identificar grupos ou pessoas. Em alguns trechos, o texto bíblico (2000: 125) indica essa idéia, como na citação a seguir:

E falou o Senhor a Moisés e a Arão, dizendo: os filhos de Israel armarão as suas tendas, cada um debaixo da sua bandeira, segundo as insígnias da casa de seus pais; ao redor, defronte da tenda da congregação, armarão as suas tendas. Os que armarem as suas tendas do lado do oriente, para 0 nascente, serão os da bandeira do exército de Judá, segundo os seus esquadrões, e Naassom, filho de Aminadabe, será príncipe dos filhos de Judá.

Tradicionalmente, os grupos de batalha diferenciavam-se pelas cores do escudo, 
como maneira de evitar um possível combate entre forças amigas por um descuido ocasional. Por exemplo, Júlio César, imperador romano, tinha como emblema uma borboleta e um caranguejo; o símbolo de Pompeu, general de Roma, era um leão segurando uma escada; Augusto, herdeiro adotivo de Júlio César, usava a esfinge como símbolo. Posteriormente, foi também necessário representar diferentes símbolos e insígnias, que eram comuns aos grupos e não somente às pessoas. As representações eram feitas em bandeiras e tinham a finalidade de representar o chefe (quando era um só que orientava os soldados) ou as cidades que os mantinham. Por exemplo, o mocho' para Atenas e a esfinge para Tebas (MATOS; BANDEIRA, 1969).

Apesar dessa tentativa de criarem-se emblemas singulares para cada grupo, não era seguida nenhuma regra rígida de construção e não eram hereditariamente claros. Qualquer indivíduo poderia adotar um símbolo, conforme gosto próprio. Assim, foi somente na Idade Média que a heráldica evoluiu, com a cavalaria européia. No entanto, não há uma definição clara de que foi nesse período que ocorreu o exato surgimento da ciência heráldica.

A percepção mais conhecida é de que a heráldica tenha surgido segundo alguns moldes, durante a época das Cruzadas². 0 fato é que, um dos símbolos heráldicos mais antigos é a cruz. Os combatentes que lutavam nas Cruzadas tinham seus escudos desenhados com a cruz, e os formatos e cores eram de acordo com as suas nacionalidades: os franceses a usavam na cor branca; os alemães nas cores laranja ou preto; os italianos, em azul; os espanhóis, em vermelho, e assim por diante.

Nas duas primeiras [cruzadas], indivíduos de regiões diferentes que tinham costumes e línguas próprias se confundiam nos acampamentos e nos campos de batalha. Com a finalidade de evitar a desordem anterior, durante a terceira Cruzada o Rei da França, Filipe II, e o da Inglaterra, Henrique II, decidiram que cada grupo se faria representar por cores próprias, facilitando o reconhecimento imediato de cada língua e a comunicação entre os componentes (TOSTES, 1983: 17).

0 registro dos símbolos heráldicos (seguindo regras e modelos) aconteceu apenas a partir do século XI. No ano de 1.111 já era possível encontrar insígnias de reis, exércitos e cidades. E no século XIII já era bem comum o uso de elementos de heráldica em famílias. Seguindo um padrão hereditário, os brasões eram utilizados até por mulheres, o que demonstra que haviam ultrapassado a idéia de distintivo de cavaleiros e tornaram-se emblemas pessoais (MATOS; BANDEIRA, 1969).

À medida que os brasões familiares foram se tornando mais populares, seu uso foi adotado, também, por regiões e países. No caso dos países, os brasões de armas eram geralmente compostos pelos brasões dos príncipes reinantes da época. E

1 Ave de rapina noturna menor que a coruja. Fonte: Moya, 1961.

2 As cruzadas foram expedições ao mundo árabe com a finalidade de reconquistar Terras Santas. Fonte: Tostes, 1983. 
quando algum território era anexado ao país, as armas desses novos países eram anexadas às armas já existentes. Deste modo, então, em vários casos podem-se perceber as conquistas e a historia de um país pelo seu escudo.

\section{Aspectos gráficos}

desde a Idade Média, a heráldica vem se desenvolvendo numa forma de organização sistêmica, iniciando-se na Europa e tomando parte de uma cultura geral que vai além de cada país. Era uma atividade globalizada que integrava toda a aristocracia européia. Nesse contexto, os brasões dos cavaleiros ou dos nobres tornaram-se suas marcas pessoais, como um método de identificação não só no território onde viviam, mas também em qualquer lugar que fossem.

Além disso, houve a categorização dos elementos gráficos que se estabeleceram como regras de composição e interpretação dos brasões. Essas regras se consolidaram como leis, regulando a construção, a proporcionalidade e a composição de brasões e bandeiras, como: brasões familiares, reais ou de armas, entre outros. Também, foram universalmente aceitas, determinando toda a sistematização heráldica.

De acordo com a primeira lei, não é permitido desenhar, por exemplo, um leão de ouro sobre um suporte de prata, e vice-versa. Quando ocorre algo desse gênero, o brasão é chamado de brasão de armas falsas.

A segunda Lei Heráldica prevê que as peças honrosas que formam o brasão devem ser colocadas nos seus devidos lugares. Uma pala, que é uma listra vertical, por exemplo, deve ocupar a linha vertical e central do escudo. Se houver várias palas, elas devem ser colocadas em posições eqüidistantes umas das outras.

A terceira Lei Heráldica prevê que as figuras naturais inseridas nos brasões, como leões ou cavalos, quando estiverem sozinhas, devem ocupar a parte central do campo, sem encostar-se às bordas.

A quarta Lei Heráldica prevê que quando muitas figuras iguais se repetem sobre 0 mesmo campo ou mesmo fundo, essas devem ter sempre o mesmo esmalte.

A quinta Lei Heráldica diz que não há tonalidades diferentes da mesma cor, como por exemplo, verde escuro e verde claro. As cinco possibilidades de esmaltes - vermelho, azul, verde, preto e púrpura, e os dois metais - ouro e prata - não variam de tons.

A sexta lei funciona mais como um conselho: um brasão deve ser simples, regular e completo. A expressão "menos é mais" se aplica aqui e, quanto mais simples for um brasão, mais nobre ele se torna.

As regras e suas exceções definem a sintaxe visual dos brasões, que é composto basicamente pelo escudo e pelos ornamentos exteriores. Todos os elementos dizem respeito ao grau nobiliárquico, à hierarquia eclesiástica ou às armas de uma cidade ou família (TOSTES, 1983). 


\section{As configurações dos escudos}

Com relação aos formatos, é dividido em dois grandes grupos: os escudos simples, que compreendem aqueles com uma só divisão, e os compostos, que apresentam diversos campos.

A forma do escudo nos desenhos heráldicos é variável em cada país. Do mesmo modo, o objeto de defesa com esse nome também era variado (MATOS; BANDEIRA, 1969).

Há o escudo com a extremidade inferior alongada, também, chamado de escudo antigo, que é um dos mais representativos de sua forma, sendo comumente usado nas marcas atuais (Fig. 1A).

Há o escudo espanhol ou português, que é representado por um retângulo, cuja parte inferior é formada como um semicírculo, com uma curva menos aguda que 0 anterior (Fig. 1B).

Há o escudo oval, que foi bastante usado por rainhas e constituintes do clero. Esse é um escudo comum na cultura inglesa, devido à tradição de sucessivos governos femininos (Fig. 1C).

Há o escudo quadrado, cuja proporção é determinada por sete partes de largura por oito partes de altura. Esse é o mesmo formato do escudo físico, comumente usado por cavaleiros nos torneios e batalhas medievais (Fig. 1D).
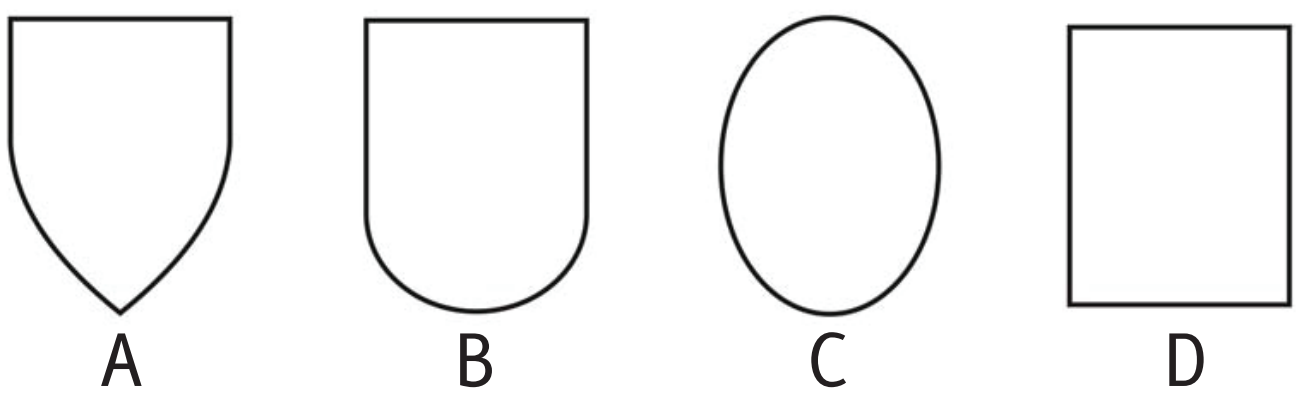

Figura 1. (A) Escudo Sanítico; (B) Espanhol ou Português; (C) Oval e (D) Quadrado Fonte: Campos (2009)

Há outros formatos além dos básicos, cujos desenhos são variações mais rebuscadas com relação às formas anteriores. 0 escudo suiço (Fig. $2 A$ ) é uma variação do modelo sanítico. A lisonja (Fig. 2B) é o nome dado ao escudo em forma de losango, a qual também é usada na decoração dos brasões. 0 escudo inglês (Fig. $2 \mathrm{C}$ ) é uma variante do quadrado. 0 escudo italiano (Fig. 2D) e mais rebuscado, sendo também denominado de barroco. 0 escudo alemão (Fig. 2E) é uma variação do espanhol ou português, sendo que, na prática, os recortes da parte superior também cumprem a função prática de apoiar a lança. 


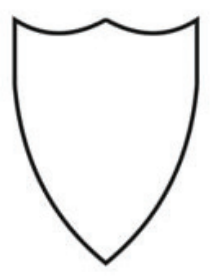

A

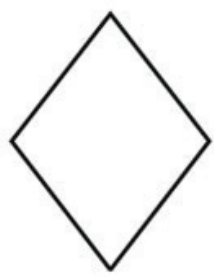

B

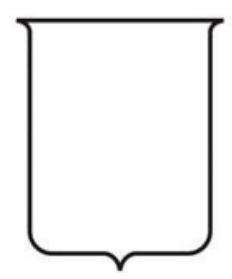

C

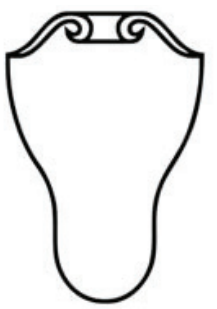

$\mathrm{D}$

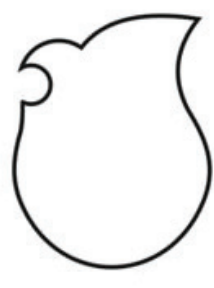

$\mathrm{E}$

Figura 2. (A) Escudo Suíço, (B) Lisonja, (C) Inglês, (D) Italiano ou Barroco e (E) Alemão Fonte: Campos (2009)

Além das diferentes configurações ou formatos, os escudos se diferenciam também por suas divisões internas. Matos e Bandeira (1969) indicam quatro categorias que são recompostas em repartições. (1) "Partido" é a primeira categoria com divisão central e vertical; (2) "cortado" é a segunda categoria com divisão central horizontal; (3) "fendido" é a terceira categoria com divisão diagonal que parte do canto superior esquerdo do observador para o canto inferior direito; (4) "talhado" é a quarta categoria com divisão diagonal que parte do canto superior direito do observador para o canto inferior esquerdo.
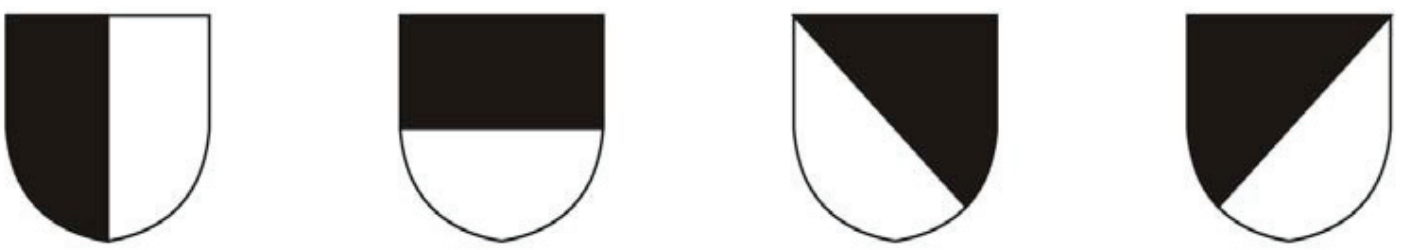

Figura 3. As quatro categorias: escudos partido, cortado, fendido e talhado Fonte: Campos (2009)

As divisões principais correspondem aos quatro grandes golpes das armas. A partir destas divisões principais, foram propostas combinações diversas como mostra o conjunto de imagens a seguir (Fig. 4).
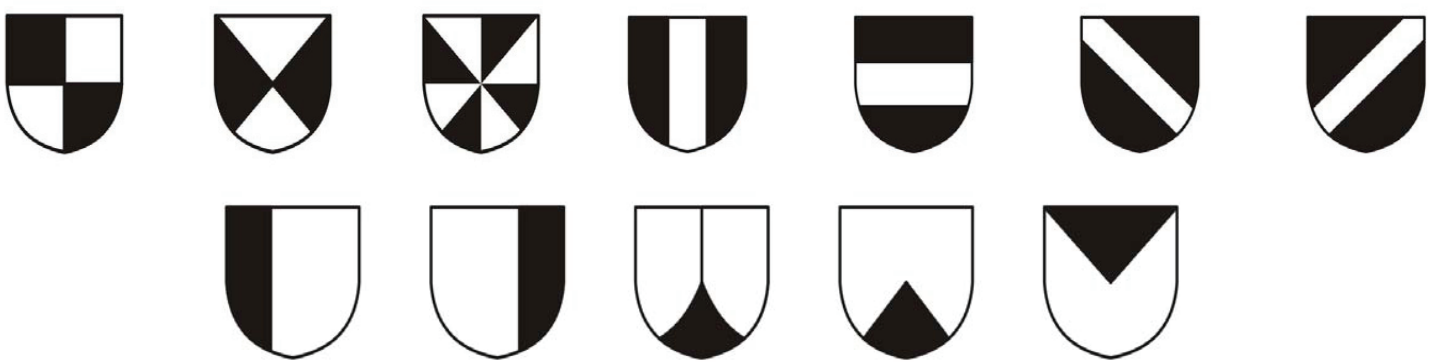

Figura 4. Variações da divisão interna dos escudos por combinações das categorias básicas Fonte: Campos (2009) 


\section{Cores, texturas e peles}

As cores dos escudos de guerra foram expressas por esmaltes, portanto, a variação desses determina, também, a variação nas sensações das cores.

Além das configurações e participações formais, as cores também são aspectos fundamentais no processo de distinção e identificação de escudos, brasões e bandeiras. Tostes (1983) observou que, no séc. XIII, os escudos traziam dois esmaltes, nem mais, nem menos. Pois, os escudos de uma só cor foram raros e, inclusive, eram mal conceituados.

0 termo esmalte também qualifica as texturas gráficas aplicadas nos escudos, sendo divididos em três grupos: (1) as cores; (2) os metais, e (3) as peles. Além do amarelo do metal ouro e do cinza do metal prata, as cores observadas são básicas e planas, com cinco variações de matiz: (1) vermelha; (2) azul; (3) Verde; (4) Preta, e (5) Púrpura.

Além das cores, observam-se a utilização de desenhos e texturas gráficas como hachuras; pontilhados e traços horizontais ou verticais. Cada tipo de hachura representa uma cor ou metal nas imagens monocromáticas. Por exemplo, o ouro é representado por pontilhado e o vermelho por listras verticais. As imagens a seguir (Fig. 5) ilustram essas variações.
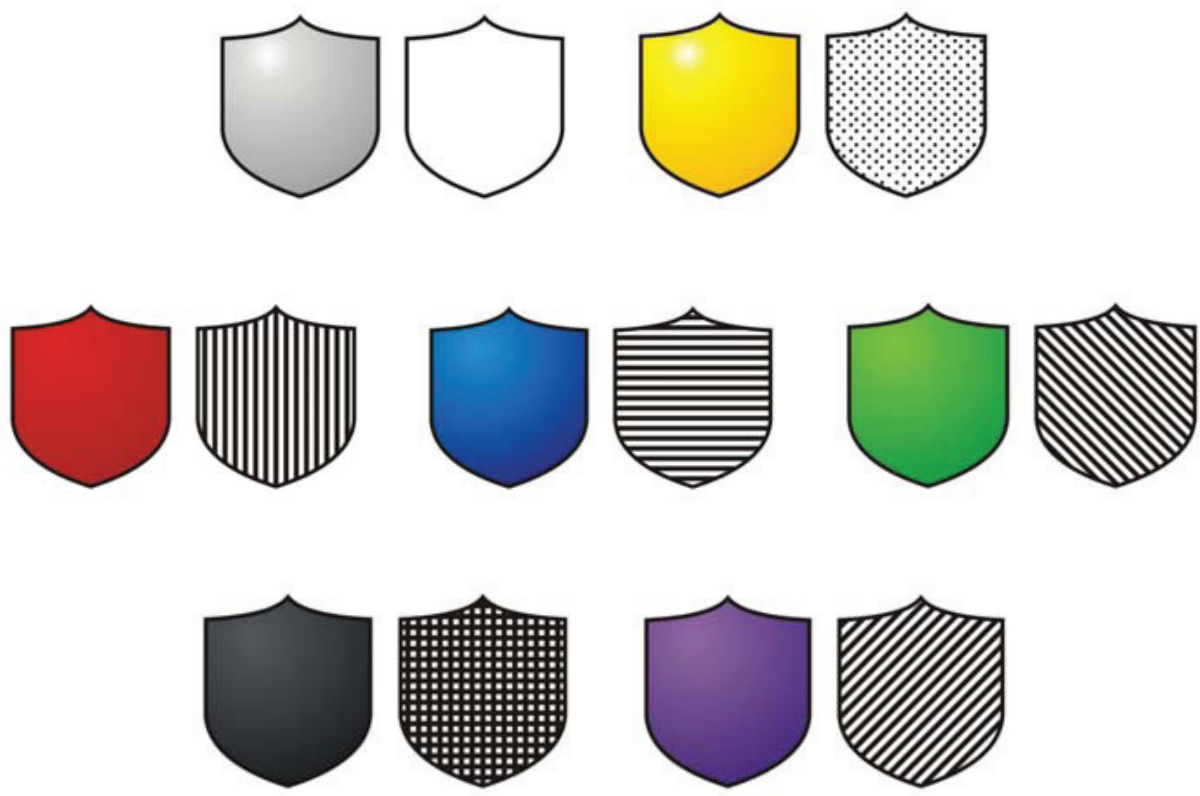

Figura 5. Variações de metais, cores e hachuras nos escudos Fonte: Campos (2009)

Além de promover sensações diferentes, os esmaltes também representam simbolismos diversificados. 0 vermelho representa a coragem, o sangue derramado e a crueldade, sugerindo valentia, nobreza e furor de vencer os inimigos. A referência do vermelho ao sangue implica na obrigação do cavaleiro defender os injustiçados 
ou oprimidos, estabelecendo uma relação com os serviços médicos na atualidade. 0 azul faz referência ao céu, à felicidade eterna, sugerindo perseverança, justiça e lealdade. 0 verde é associado à força, também, sugerindo civilidade, alegria, cortesia e amizade A associação com a esperança é relacionada à agricultura que verdeja antes da colheita. 0 preto simboliza fortaleza, constância, tristeza, luto e dor, representando também a ideia de desafio e rebeldia. A cor púrpura representa tranquilidade, riqueza, triunfo e devoção. Historicamente, essa cor foi reservada aos membros das classes superiores, sendo de uso exclusivo ou restrito. 0 ouro indica nobreza, riqueza, poder e solidez. A prata é associada com limpeza, integridade, franqueza, podendo vencer batalhas sem derramar sangue.

Os diferentes padrões de desenhos dispostos sobre os escudos foram denominados como "peles". Tradicionalmente, há duas peles sendo uma dessas denominada de "veiro" e a outra de "arminho".

0 "veiro" foi baseado na pele de um tipo de esquilo de barriga branca e costas azul-acinzentadas, que é encontrado na África. Isso justifica a cor azul e o metal prata, nos escudos que são estampados com campânulas ou formas de sino. Porém, o mesmo padrão aparece em outras cores, quando isso acontece o escudo recebe a qualificação de "veirado". Este tipo de pele indica proeminência de honras, dignidade notável ou grande nobreza.

0 "arminho" é baseado na pele do animal de mesmo nome, que é originário da Armênia, cuja pelagem branca escurece na ponta da cauda em formato de flecha. Isso justifica a base prata do escudo recoberta com pontas de flecha ou "mosquetas" pretas. Porém, há também o padrão inverso que é denominado de "contra-arminho". Quando o padrão gráfico é repetido com outras cores o escudo é chamado de "arminhado". Este tipo de pela indica alta dignidade, sendo usado nas vestes das autoridades mais eminentes (MOYA, 1961). 0 conjunto de imagens a seguir (Fig.6) mostra a variedade de peles nos escudos.

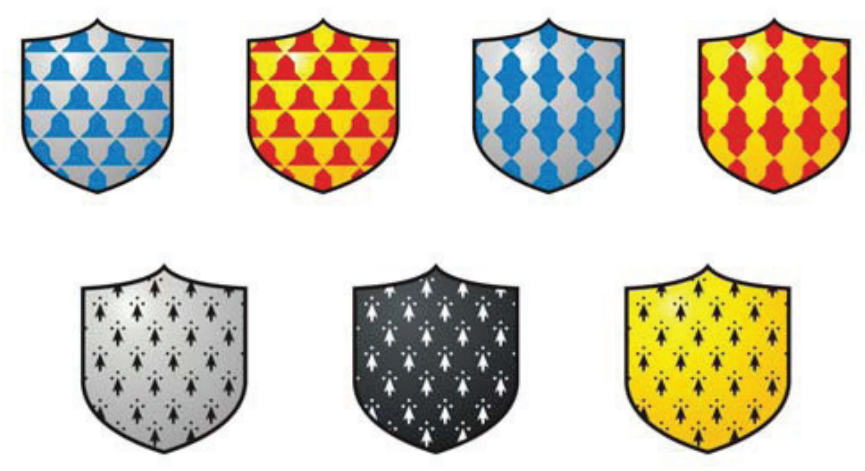

Figura 6. Variações de peles "veiro" e "veirado", "arrminho", "contra-arminho" e "arminhado" Fonte: Campos (2009) 


\section{Figuras heráldicas}

As figuras heráldicas estão presentes desde o início da arte de elaborar os brasões. Elas aparecem principalmente em decorrência do esgotamento das combinações geométricas que se faziam nos escudos. Assim, os reis-de-armas, responsáveis por criar os escudos e brasões tiveram a necessidade de incorporar figuras que passaram a assumir um simbolismo com espiritualidade e virtudes (TOSTES, 1983).

Há grupos de figuras naturais, artificiais ou fantásticas. Porém a cruz e os elementos celestes não compõem um grupo especifico, mas estão constantemente presentes nos brasões, indicando inclusive a relação original entre a arte heráldica e as Cruzadas. A "cruz heráldica" tradicional apresenta braços e haste de mesma espessura, acompanhado as proporções do escudo. A "cruz de Jerusalém" apresenta extremidades barradas e mais quatro cruzetas. A "cruz florenciada" apresenta as extremidades com formas semelhantes à flor-de-lis. A "cruz de Malta" apresenta braços que se estreitam em direção ao centro e suas extremidades são chanfradas. Esses tipos de cruz (Fig. 7) aparecem com mais constância, todavia, são observadas diversos outros tipos.
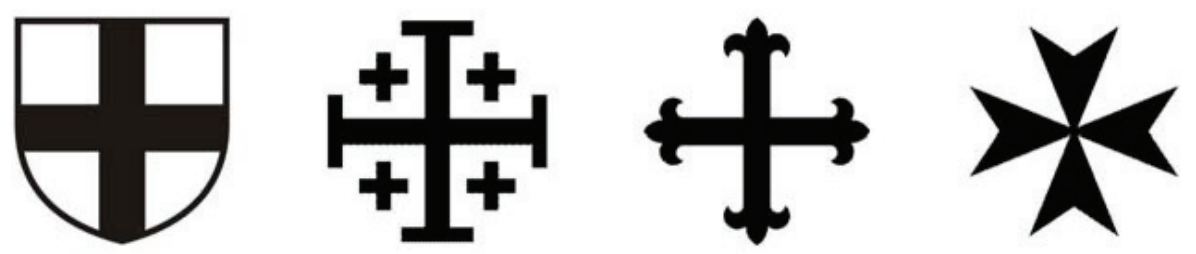

Figura 7. "Cruz tradicional", "Cruz de Jerusalém", "Cruz Florenciada" e "Cruz de Malta" Fonte: Campos (2009)

0 conjunto das figuras naturais reúne animais, vegetais e figuras humanas, agrupando um grande número de representações. Entre as figuras de animais, destacam-se a águia e o leão. Porém, existem brasões com inúmeros tipos de animais, desde leopardos, raposas, lobos, cavalos, cachorros, javalis, cabras, falcões, até galos, pavões, cisnes, golfinhos ou peixes. Enfim, é permitido qualquer animal ou figura natural que se queira representar, de acordo com o significado e as características coerentes com o representado pelo brasão. Além da águia e do leão, o grupo de imagens a seguir (Fig. 8) apresenta também outros animais.

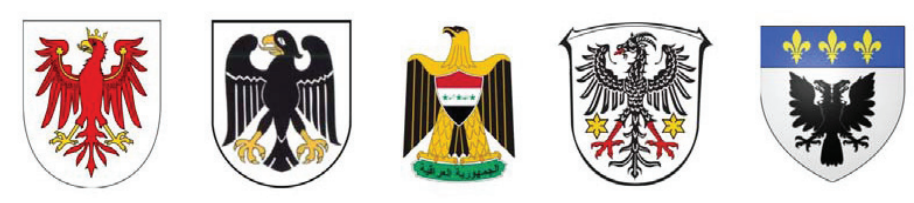




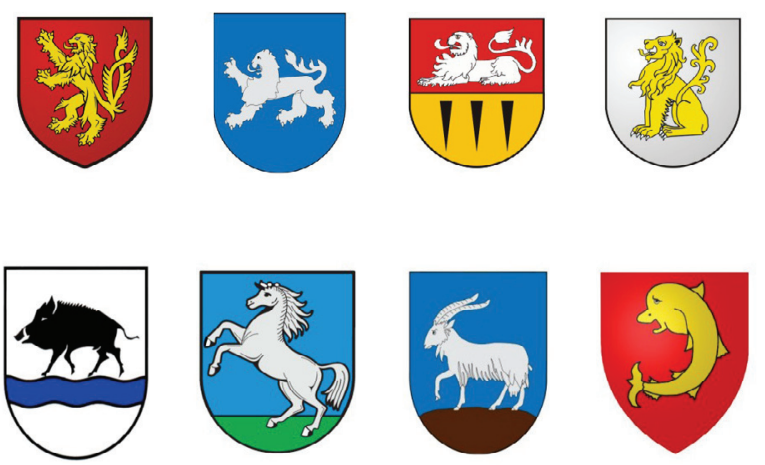

Figura 8. Figuras naturais: animais Fonte: Campos (2009)

Outras figuras naturais são os vegetais, como árvores, folhas e flores. Inicialmente foram usados de maneira limitada, com poucas variações dos tipos representados. Muitas vezes são difíceis de serem especificamente identificados, mostrando-se como vegetais genéricos. As árvores são reconhecidas pelas folhas e frutos, mas são apresentadas de maneira indefinida. As flores indicam peças naturais mais ornamentais. Porém, a rosa é considerada tão importante quanto o leão na terra ou a águia no céu, aparecendo em brasões com cinco pétalas entremeadas por cinco pequenas folhas verdes. A flor-de-lis, de origem francesa, também é desenhada e parece ser mais recorrente que a rosa, especialmente nos brasões brasileiros. Além dessas, são encontradas representações de flores como camélia, cravo, girassol, lírio, tulipa e violeta (Fig. 9).
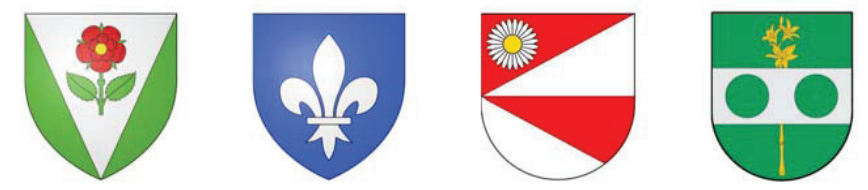

Figura 9. Figuras naturais - flores Fonte: Campos (2009)

As figuras humanas ou partes dessas figuras também fazem parte da categoria de figuras naturais, sendo que essas são representadas, com as cores próprias. Nos exemplos medievais, quando a figura humana aparece completa, geralmente, está vestida com armadura e armado para combate. Porém, há exemplos mais recentes, como o brasão que representa a cidade Florianópolis, que apresenta duas figuras humanas e um escudo coroado (Fig. 10).

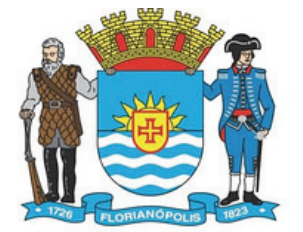

PREFEITURA MUNICIPAL DE FLORIANÓPOLIS
Figura 10. Brasão da cidade Florianópolis Fonte: Sítio oficial da prefeitura da cidade Florianópolis 
Os reis são representados com a cabeça coroada. As imagens que representam a cabeça dos reis nos escudos influenciaram na tradição de apresentar rostos de reis, primeiramente em moedas, mas também em notas de dinheiro. Construções arquitetônicas e outros objetos culturais também são comumente representados. Por exemplo, Matos e Bandeira (1969) indicam que os castelos são representados com três torres e muralha aparente na frente. A imagem do castelo é recorrente nos brasões de cidades Símbolo da nobreza antiga indica o poder e a dignidade feudal e eram bastante freqüentes nos selos dos senhores feudais e das cidades. Há também representações de navios ou barcos, além de armas, elmos, coroas e diversos outros objetos relacionados ao mundo feudal e sua hierarquia social (Fig. 11).
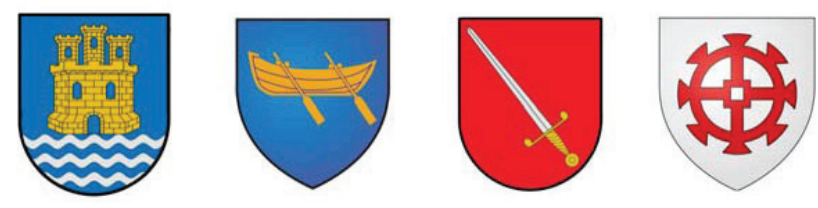

Figura 11. Figuras artificiais: castelo, barco, espada, timão Fonte: Campos (2009)

Há ainda as representações de seres míticos, como sereias, unicórnios e dragões, sendo que, entre essas, o dragão é a figura mais recorrente na tradição heráldica (Fig. 12). Representações dos astros celestes, especialmente o sol, a lua, os cometas e as estrelas em geral (Fig. 12), também participam dessa tradição, compondo o grupo de elementos celestes (TOSTES, 1983). 0 sol desenhado com feições humanas ocupa o lugar de figura celeste mais importante e tem sido observado seu uso em todas as épocas.
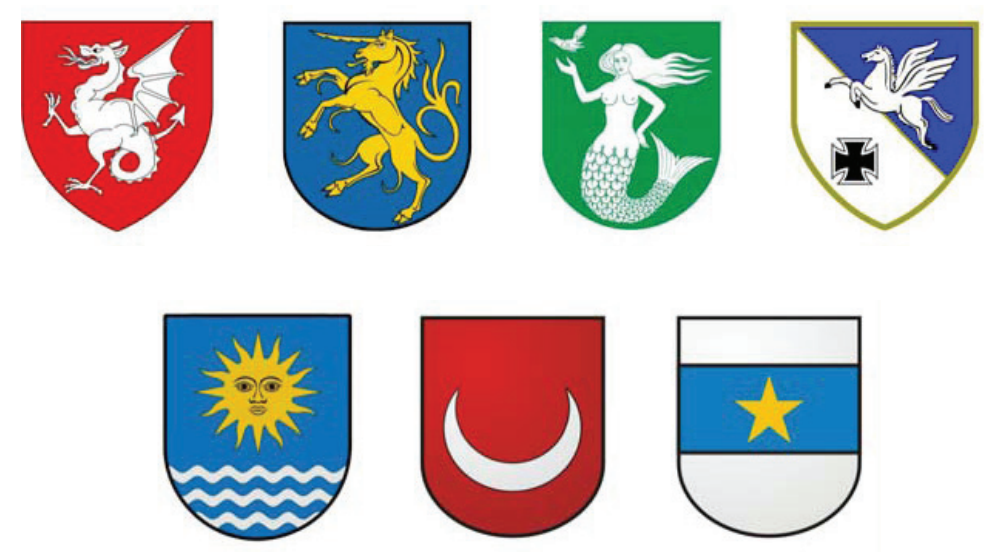

Figura 12. seres míticos e astrais: dragão, unicórnio, sereia, cavalo alado, sol, lua, estrela Fonte: Campos (2009) 


\section{Caracterização dos aspectos gráficos}

Os princípios gráficos da representação heráldica são estabelecidos de maneira plenamente racional, sendo que suas configurações de base são determinadas através das relações geométricas e de representações figurativas estilizadas, com base na simplificação.

Há diferentes maneiras de representação dos símbolos visuais. Por exemplo, uma fotografia pode ser muito semelhante ao que o olho humano vê e, por ser uma representação da realidade visível, a fotografia é um símbolo do modelo visto, porque não é o próprio modelo. Porém, é um símbolo que pretende ser percebido como o próprio modelo que representa.

Ao contrário da fotografia, as representações heráldicas são símbolos propriamente ditos, por serem compostos por figuras geométricas, que são simbólicas por si mesmas, ou por figuras de seres naturais ou míticos e de objetos culturais, as quais são desenhadas de maneira estilizada ou simplificada, evidenciando o caráter simbólico.

Além das figuras recorrentes na arte heráldica serem desenhadas de maneira simbólica, essas também são carregadas de significados culturais, cuja amplitude é universal e a sua evolução simbólica veio sendo desenvolvida ao longo do tempo, desde as comunidades humanas mais primitivas.

As expressões gráficas da arte heráldica se apresentam como um marco da cultura medieval, todavia, seus símbolos e seus processos de representação antecedem em muito o período medieval e ainda repercutem na cultura atual, especialmente na cultura simbólica das marcas institucionais e comerciais. Para Frutiger (2007: 200) os atributos simbólicos consolidam-se como alegorias:

A combinação da figura histórica com o objeto carregado de significado simbólico resulta numa expressão abstrata e de fato alegórica. Sendo assim, a forma feminina alada, por exemplo, simboliza em geral a vitória e a liberdade, enquanto o chifre cheio de frutas é uma alegoria para a riqueza e a abundância.

Há, portanto, uma cultura dos símbolos que é conservada e propagada nas marcas gráficas, começando com as primeiras inscrições rupestres, avançando até consolidar sistemas iconicamente formalizados e regulamentados como na arte heráldica e se perpetuando através do tempo, inclusive, nas marcas institucionais e comerciais da atualidade. Assim, a cultura histórica de toda a humanidade e, no caso em estudo, a cultura do ocidente é percebida e tratada como um amplo repositório de sinais e símbolos que alimentam e ordenam o imaginário público e, também, afetam diretamente o imaginário do público consumidor. 


\section{Heráldica de corporações e marcas}

A arte heráldica está presente nos elementos gráficos de identificação e representação de corporações militares, comerciais, desportivas, entre outras. Assim como outros grupos e divisões, este ramo da heráldica procurou representar em brasões, bandeiras e marcas, as qualidades distintivas de uma determinada instituição.

A heráldica de corporações militares está diretamente ligada à época dos confrontos medievais, mas se estende à atualidade. Os regimentos de exércitos portam um estandarte com formas e cores, que simbolizam a alma da corporação, sendo que essa bandeira é levada em conjunto ao campo de batalha. 0 estandarte é defendido por todos, até o último sobrevivente, pois perdê-lo significa a maior desonra para o regimento.

Segundo Matos e Bandeira (1969: 56), “as diferentes Ordens militares nacionais também tinham os seus emblemas próprios, em regra representados nas bandeiras". Assim, os símbolos heráldicos permanecem estampados nas corporações militares e em outras instituições ou corporações. Podendo ser compostos de acordo com as regras tradicionais ou serem recompostos como elementos participantes de outras ordens compositoras de símbolos.

A representação das corporações comerciais também descende da heráldica, apesar de haverem registros históricos de marcas muito antigas. Pois, os parâmetros gráfico-simbólicos das marcas comerciais, como são percebidas na atualidade, foram definidos na época dos brasões de famílias de artesãos e comerciantes, considerando-se nos símbolos elementos referentes aos produtos comercializados ou a iniciais do fabricante, entre outros. Matos e Bandeira (1969: 57) contam que, devido ao uso comum de brasões nesse período, os produtos de qualquer espécie não poderiam ser comercializados com brasões de armas nacionais ou municipais.

0 desenho das marcas gráficas atuais costumam fazer alguma referência à estética ou a simbologia heráldica, valendo-se dos valores estético-semânticos já consolidados na tradição das armas e brasões. Os emblemas de times e corporações, tradicionalmente, são escudos (Fig. 13), como o da seleção brasileira.

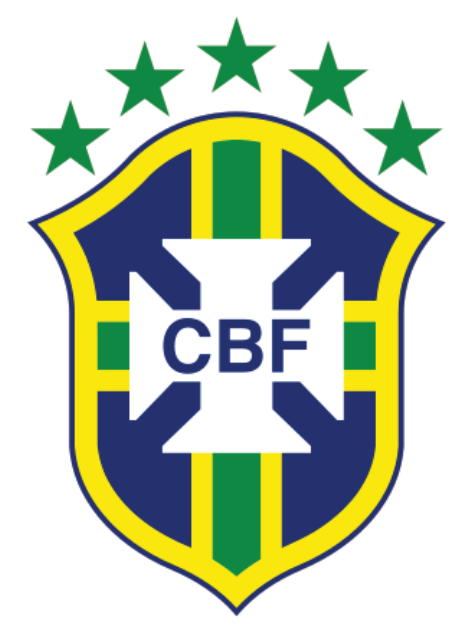

Figura 13. Escudos de futebol: Confederação Brasileira de Futebol Fonte: AIMORÉ, 2012. 
As equipes de carros de corridas são denominadas de "escuderias". As composições gráficas das escuderias são influenciadas e influentes nas marcas gráficas de automóveis e montadoras. Há que se considerar, inclusive, que essas marcas institucionais são atualmente administradas para desempenhar as funções de grandes marcas comerciais, identificando também amplas e diversificadas linhas de produtos.

As marcas que buscam qualificar seus produtos com atributos de nobreza e sofisticação aliados à tradição recorrem constantemente aos elementos heráldicos. As marcas de bebidas, como cerveja, vinho, whisky e vodka, apropriam-se dos elementos convencionais ou citam a arte heráldica de maneira recorrente A marca de vodka Orloff (Fig. 14) apresenta como seu símbolo de identidade a águia bicéfala, que é um elemento típico da heráldica russa. A marca de cerveja Bohemia (Fig. 15), também, apóia-se na tradição, apresentando-se como a primeira cerveja do Brasil.
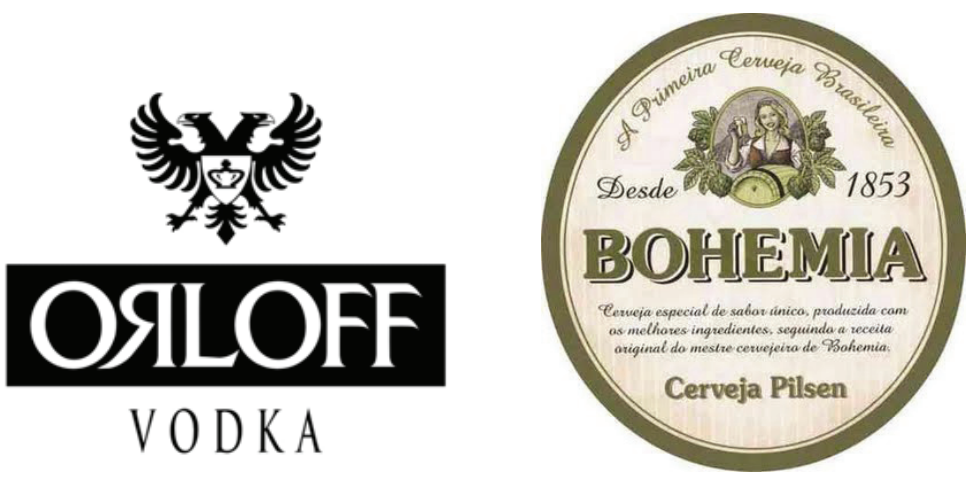

Figura 14. Marca Orloff e rótulo da cerveja de marca Bohemia Fonte: Campos (2009)

Além da citação direta, com uso de elementos já configurados, as marcas mais antigas, especialmente as criadas e divulgadas antes da década de 1980, registram influencias da base gráfico-compositora e simbólica arte heráldica. Por exemplo, nas imagens a seguir (Fig. 15) são apresentadas marcas gráficas que apresentam molduras estilizadas associadas aos escudos que originaram toda a tradição dos emblemas, insígnias e botons.
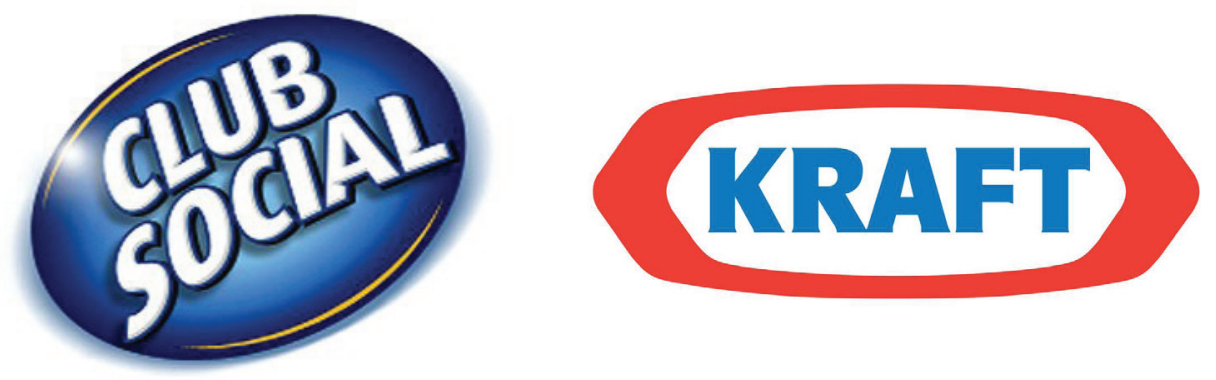

Figura 15. Marca gráfica dos biscoitos Club Social e marca gráfica dos alimentos Kraft Fonte: Campos (2009) 
Além da relações visuais, há também a influência dos aspectos simbólicos, Baxter (1998) faz referência às marcas alemãs de carros, dizendo que essas têm anéis de aço ao seu redor representando integridade, força e qualidade, refletindo também as qualidades funcionais da indústria alemã (Fig. 16).
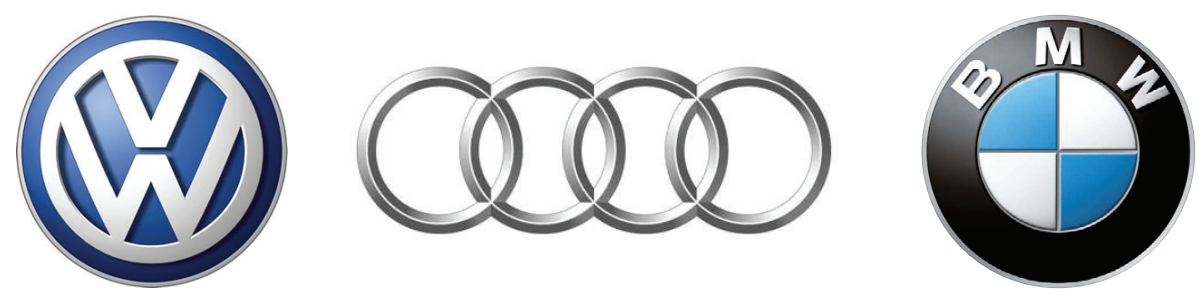

Figura 16. Marcas alemãs de automóveis - Volkswagen, Audi e BMW Fonte: Campos (2009)

Diante do exposto, considera-se que, referente à construção de marcas gráficas e outros símbolos institucionais e comerciais e os processos gráficos na modernidade são decorrentes e devedores da base heráldica medieval. Essa base subsistiu a Revolução Industrial e à estética funcionalista, determinando em parte e também influenciando o design modernista.

Atualmente, com a popularização e consolidação dos recursos da computação gráfica, percebe-se sintomas de uma estética diferenciada com relação aos princípios tradicionais da heráldica. Essa tendência aparece, inclusive, nas marcas de cidade e país que são destinadas a representar esses lugares na cultura do turismo global. Um exemplo disso é a própria marca Brasil (Fig. 17), cujas formas fazem referência à obra do artista e paisagista brasileiro Burle Max (1909-1994). A marca turística Brasil entre outras de diferentes cidades e países fazem referências à cultura, à paisagem ou à geografia local. Porém, essa referência é praticamente implícita, sobressaindo os aspectos estéticos da mensagem sobre seu conteúdo simbólico-convencional. A marca de Espanha (Fig. 17) faz referência direta ao artista Joan Miró (1893-1983), porém a obra do artista não é figurativa e seu simbolismo é muito indireto. Além disso, essas e outras marcas atuais de cidades e países (Fig. 17), não apresentam escudos ou molduras. Mas o aspecto mais inovador advém dos recursos digitais que, agora, permitem com facilidade a reprodução gráfica dos efeitos de transparência cromática, como aparece na marca Brasil e na marca do portal de internet Terra (Fig. 17).
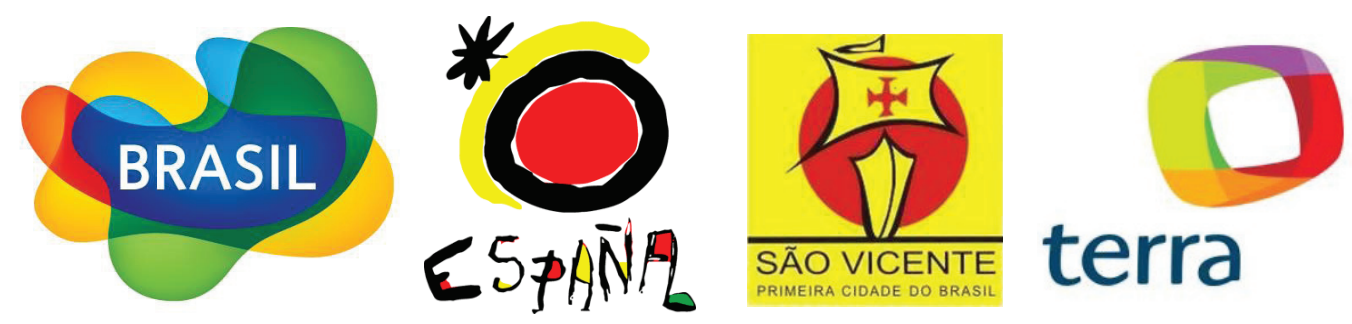

Figura 17. Marcas turísticas: Brasil; Espanha; São Vicente. Marca do portal Terra na internet Fonte: Campos (2009) 
Há influências heráldicas nas imagens das marcas gráficas apresentadas (Fig. 17), confirmando a influencia cultural da arte em questão. Porém, a marca da cidade de São Vicente, que se apresenta como "primeira cidade do Brasil", corrobora de modo explícito a ideia de que as marcas apoiadas na tradição fazem referências a formas e figuras heráldicas, de maneira recorrente. As outras marcas, que são as marcas turísticas de Brasil e Espanha e, também, a marca do portal Terra, afastam-se da estética geométrico-formalista e figurativa da heráldica. Mesmo as marcas mais ordenadas, que são a marca Brasil e a marca Terra, apresentam ordenação no recorte das formas, mas mostram desordem assimétrica e expansiva nas posições e nos ritmos das figuras. Além disso, essas marcas gráficas promovem sensações de leveza e transparência, as quais não caracterizam a tradição heráldica.

\section{Considerações finais}

A função das marcas gráficas é similar a dos brasões, porque ambos servem para identificar, distinguir e representar pessoas, famílias, instituições e empresas comerciais, atribuindo-lhes valores simbólicos, de maneira positiva e idealizadora. Agora, há plena liberdade de criação e recursos gráficos de alta tecnologia estão disponíveis. Apesar disso, as formulações gráfico-visuais de formas ou figuras e a simbologia heráldica, ainda, influenciam de maneira direta ou indireta o design de identidade visual da marca. Essas formulações e simbologias são expressas, principalmente, nas marcas gráficas tradicionais ou nas que consideram e apresentam a tradição como valor de marca.

Escudos e figuras heráldicas tradicionais fizeram parte das artes gráficas modernas e do design gráfico modernista. Pode-se perceber um processo de resgate dos valores heráldicos e, também, outros procedimentos menos ortodoxos que consistem na apreensão e na recomposição simbólica, como uma bricolagem de símbolos, os quais até antecederam à cultura heráldica medieval, compondo uma iconografia histórica global e, mais especificamente, ocidental.

A linguagem simbólica da heráldica foi o sistema mais eficiente de comunicação, no período que o imediatismo na identificação de uma marca contrapunha os níveis de analfabetismo da população. Letrados eram poucos; cavaleiros eram muitos. Atualmente, as marcas manifestam interesses semelhantes, porque buscam seu reconhecimento e sua fixação na mente do público, desde antes do processo de alfabetização dos consumidores.

Há sinais, entretanto, de substituição na abordagem informativa e comunicativa das marcas, em sentido contrário ao processo predominantemente comunicativo da tradição heráldica e da própria tradição do design gráfico modernista. Pois, o processo de expressão estética parece estar sendo mais valorizado que o processo de comunicação simbólica. 0 exemplo é caso da marca turística Brasil (Fig. 18), porque além do nome as formas compõem uma figura dinâmica, leve e transpa- 
rente, mas que não faz referência direta a nenhum elemento histórico-cultural, paisagístico ou geográfico que possa ser imediatamente identificado. Marcas com figuras abstratas como triângulos ou quadrados foram comuns na arte heráldica e no design modernista. Porém, nessas marcas, há a definição geométrica e o simbolismo tradicionalmente definido de cada figura. Todavia, o mesmo não acontece na marca Brasil, sugerindo a configuração de uma abordagem diferente da tradição. 


\section{Referências}

> AIMORÉ, Coelho. Escudos de times de futebol do Brasil. [on-line] Disponível em: [http://aimore.org/escudos/geral.html]. Acesso em: 09/abril/2012.

$>$ ATELIER HERALDICO. Introdução ao estudo sobre Heráldica. [on-line] Disponível em: [http://www.atelierheraldico.com.br/heraldica/index.htm]. Acesso em: 10/outubro/2011.

> BAXTER, Mike. Projeto de Produto: guia prático para o design de novos produtos. 2. ed. São Paulo: Edgar Blücher Ltda., 1998.

> CAMPOS, André R. P. de. Heráldica: um retrato da arte dos brasões. 2009. $83 \mathrm{f}$. Dissertação (Graduação). Curso de Graduação em Design, Universidade do Estado de Santa Catarina, Florianópolis: 2009.

> CASA Imperial do Brasil. Bandeiras Históricas. [on-line] Disponível em: [http:// www.monarquia.org.br]. Acesso em: 15/outubro/2011.

> COSTA, J. A imagem da marca: Um fenômeno social. São Paulo: Rosari, 2008.

> FERNANDES, Aníbal de Almeida. Heráldica: origens, símbolos, desenhos e sua presença no séc. XXI. Jornal Brasileiro de Cultura. [on-line] Disponível em: [http:// www.jbcultura.com.br/Anibal/healdica.htm]. Acesso em: 03/novembro/2011.

$>$ FRUTIGER, Adrian. Sinais e símbolos: desenho, projeto e significado. Tradução Karina Jannini. São Paulo: Martins Fontes, 2007.

> MATOS, Gastão de Mello de; BANDEIRA, Luís Stubbs Saldanha Monteiro. Heráldica. 363. ed. Lisboa: Verbo, 1969.

> MOZOTA, Brigitte Borja de; KLÖPSCH, Cássia; COSTA, Filipe Campelo Xavier da. Gestão do design: usando o design para construir valor de marca e inovação corporativa. Porto Alegre: Bookman, 2011.

> MOYA, Salvador de. Simbologia Heráldica: Suplemento da Revista Genealógica Latina. São Paulo: Instituto Cenealógico Brasileiro, 1961.

> PERASSI, R. Introdução ao estudo de Branding. Florianópolis: UFSC, 2010 (Préprint).

> PERASSI, R. A visualidade das marcas institucionais e comerciais como campo de significação. (Tese de doutoramento). Comunicação e Semiótica, Pontifícia Universidade Católica, São Paulo: 2001.

> PIGNATARI, Décio. Semiótica da arte e da arquitetura. 3š Ed. Cotia: Ateliê Editorial, 2004.

> STRAUB, Ericson; GUIMARÃES, Mariana Di Addario. Heráldica - símbolos nobres, significados. Revista ABC Design. Curitiba, Nć 20, jun.2007. p.12-16. 
André Ricardo Paim de Campos, Especialista em Gestão de Design pela Universidade Federal de Santa Catarina - UFSC

arpcampos1@hotmail.com

Eduardo Napoleão, mestrando em Design e Expressão Gráfica pela Universidade Federal de Santa Catarina - UFSC

eduardonapoleao@yahoo.com.br

Richard Perassi Luiz de Sousa, Professor do curso de Design da Universidade Federal de Santa Catarina - UFSC

richard.perassi@uol.com.br 